\title{
Spectrum of hysterosalpingographic findings among women presenting with infertility in Abuja, Nigeria's capital
}

\author{
Ukamaka D. Itanyi*, Hadijat O. Oluseyi
}

Department of Radiology, University of Abuja Teaching Hospital, Gwagwalada, Abuja, Nigeria

Received: 14 February 2017

Accepted: 07 March 2017

\section{*Correspondence:}

Dr. Ukamaka D. Itanyi,

E-mail: amakaitanyi1995@gmail.com

Copyright: (C) the author(s), publisher and licensee Medip Academy. This is an open-access article distributed under the terms of the Creative Commons Attribution Non-Commercial License, which permits unrestricted non-commercial use, distribution, and reproduction in any medium, provided the original work is properly cited.

\section{ABSTRACT}

Background: Hysterosalpingography HSG provides the outline of the endometrial canal and fallopian tubes and is an invaluable imaging modality in the investigative management of infertility especially in resource challenged environments. The objective of the study was to review the hysterosalpingographic (HSG) findings in women investigated for infertility in Abuja, Nigeria's capital.

Methods: This is a descriptive review of retrospective radiologic reports of 219 patients who underwent HSG as part of infertility investigation over a three-year period (2013-2015) in University of Abuja teaching Hospital.

Results: A total of 219 reports were reviewed with age range of 20-53years (mean $33.9 \pm 5.7$ 2SD) years. Majority were between the ages of $26-37$ years $(n=102,33.6 \%)$. Secondary infertility was the indication in $172(78.5 \%)$ and primary infertility in $47(21.5 \%)$. Majority of the women $(n=149,68 \%)$ had hysterosalpingographic abnormalities with Tuboperitoneal pathology as the prevalent finding in $112(75.2 \%)$ of the cases either as a single pathology or coexisting with intrauterine abnormality. The most common endometrial cavity abnormality was uterine Fibroid seen in $53,(35.6 \%)$ women.

Conclusions: Hysterosalpingography remains very important in the investigation of infertility in our center with tuboperitoneal pathology as the major contributor to female infertility.

Keywords: Endometrium, Fallopian tubes, Hysterosalpingography, Infertility

\section{INTRODUCTION}

Infertility is a global public health problem with incidence varying from one region of the world to the other, being highest in the so-called infertility belt of Africa which includes Nigeria. ${ }^{1}$ This has been attributed to a high rate of sexually transmitted infections, complications of unsafe abortions, and puerperal pelvic infections ${ }^{2}$ Infertility is a major gynecological complaint in Nigeria. This is because of the sociocultural effects on the families involved. It leads to disunity, depression, infidelity, separation and sometimes divorce. An infertile couple in sub-Saharan African is usually stigmatized and not often regarded as complete. Mechanical factors are responsible for approximately $30 \%$ of female infertility and various methods such as transvaginal ultrasonography, hysterosalpingography (HSG), hysteroscopy and laparoscopy have been used to investigate these factors. ${ }^{3} \mathrm{HSG}$ is widely used to investigate the morphology of uterine cavity and establish the patency of fallopian tubes. To properly manage a case of infertility, it is crucial to establish the patency of the Fallopian tubes. Hysteroscopy and laparoscopy with chromopertubation (HLC) is now the gold standard because of its improved ability to assess the uterine cavity, establish the tubal status and possibility for proper treatment. ${ }^{4}$ However, in Nigeria, the positive contrast agents used for this investigation are not readily available with the added dearth of skilled personnel. These investigations are also very expensive in the few centers 
where they are available. Hysterosalpingography therefore remains the mainstay and frontline investigation of infertile patients while sonohysterography is rarely done. $^{5}$ Even though laparoscopy is considered as the reference standard in infertility workup, HSG can be performed first and the use of laparoscopy should be limited to cases suspected for etiologies other than intra tubal, such as endometriosis and peritubal adhesions. ${ }^{6}$ The high specificity of hysterosalpingography makes it very helpful for ruling out tubal disease, even where endoscopic evaluation is available. ${ }^{6,7} \mathrm{HSG}$ is less invasive and enhances fertility in select situations. ${ }^{7,8}$ Endometrial Contour abnormalities and filling defects in HSG can be a pointer to congenital abnormalities, uterine fibroids, polyps and intrauterine adhesions. HSG can be diagnostic on its own or lead to further investigations like ultrasonography, sono hysterosalpingography (SHSG) and MRI. This is because it has its limitations which include ionization of tissue and inability to show the walls of the Uterus and the surrounding adnexia.

There is a paucity of data on the diagnostic yield and usefulness of HSG in infertility management at the University of Abuja, hence the need for the study to fill the existing knowledge gap.

\section{METHODS}

This was a descriptive study involving review of retrospective data of HSG findings in women referred to the Department of Radiology of the University of Abuja Teaching Hospital, Abuja for infertility investigation over a three-year period (August 2013 to July 2016). The hospital is located in a major town along an intercity highway and basically provides services to the population within Nigeria's Capital and the surrounding states. The written radiologic reports and some archived images from the PACS were assessed. Demographic and clinical data were obtained from patients' records and radiological reports. Our departmental protocol includes signed consent from all patients. The HSGs were performed in the proliferative phase of the menstrual cycle to rule out pregnancy and ensure that the endometrium is thin for better evaluation. All patients received $10 \mathrm{mg}$ of Buscopan antispasmodic injection, before each examination, in-order to eliminate false or physiological fallopian tube blockage due to cornual spasm. Control film of the pelvis was obtained in an anteroposterior projection for proper positioning and technical review. 15-40mls of Water-soluble contrast media was instilled into the endometrial canal under aseptic technique. Anteroposterior and oblique views were taken for evaluation depending on the radiologist's discretion. A series of images were captured as contrast flowed through the genital tract. These included: early filling phase to capture small filling defects, distended endometrial cavity phase to assess the uterine cavitary morphology, tubal phase which outlined the tubes and spillage into the peritoneal cavity and the delayed phase for further assessment in cases of loculation. Cases with contrast intravasation, reflux and ambiguous information were excluded from the study.

All the examinations were reviewed and reported by the radiologist and soft copy viewed in the PACS.

\section{Statistical analysis}

SAS software (SAS Institute, Cary, North Carolina, USA) version 9.3 was used for analysis. Graphical illustrations were done with SAS and MS Excel.

\section{RESULTS}

A total of 304 films and reports were recorded within the period but 219 cases that met the criteria were included in the study. The age range of the participants was from 2053years with a mean of $33.9 \pm 5.62$ SD years. Majority of the participants were between the ages of 26-37 (68\%). There was no significant difference between the ages of women who had normal and abnormal HSG findings $(\mathrm{p}=0.295)$. See Figure 1 and Table 1.

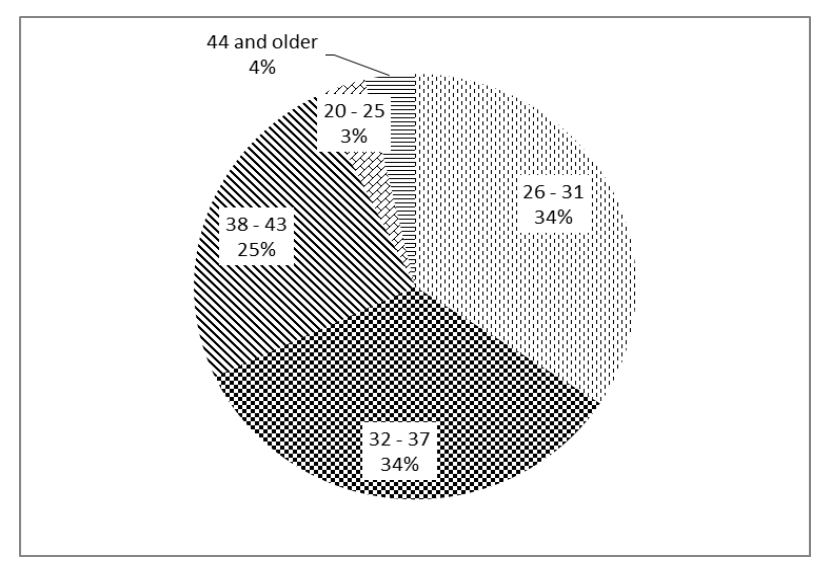

Figure 1: Distribution of patients by age group.

Table 1: Baseline characteristics for age.

\begin{tabular}{|lcccccc|}
\hline Variable & Mean & SD & Min & Med & Max & P-value \\
\hline Age (years) & \multicolumn{7}{c}{} & & & & \\
\hline All & 33.9 & 5.6 & 22.0 & 34.0 & 53.0 & 0.2959 \\
\hline Normal HSG & 33.6 & 5.7 & 24.0 & 33.5 & 48.0 & 0.0 \\
\hline Abnormal HSG & 34.0 & 5.7 & 22.00 & 34.0 & 53.0 & \\
\hline
\end{tabular}

P-value is MWW two-sample test for comparing mean age between women with normal and abnormal HSG finding. 
A greater percentage of women presented with secondary infertility ( $78.5 \%$ vs. $21.5 \%$ ). Majority of the 172 women diagnosed with secondary infertility were in the 32 to 37 year-old age group $(n=65,37.8 \%)$ while the primary infertility group were in a younger age group, 26 to 31 year-old $(n=23,48.9 \%)$. See Table 2. Majority of the women were diagnosed with abnormal HSG findings $(68.0 \%$ vs. $32.0 \%)$ with a higher percentage of abnormality seen in secondary infertility $(81.2 \%$ vs $18.8 \%)$.

Table 2: Pattern of indications for hysterosalpingography.

\begin{tabular}{|lll|}
\hline Age group & Indication for HSG \\
& $\begin{array}{l}\text { Primary infertility } \\
(\mathrm{N}=47,21.5 \%)\end{array}$ & $\begin{array}{l}\text { Secondary } \\
\text { infertility }(\mathrm{N}=172 \\
78.5 \%)\end{array}$ \\
\hline $\mathrm{n}(\%)$ & & $6(3.5)$ \\
\hline $20-25 \mathrm{y}$ & $2(4.3)$ & $52(30.2)$ \\
\hline $26-31 \mathrm{y}$ & $23(48.9)$ & $65(37.8)$ \\
\hline $32-37 \mathrm{y}$ & $9(19.2)$ & $43(25.0)$ \\
\hline $38-43 \mathrm{y}$ & $11(23.4)$ & $6(3.5)$ \\
\hline $\begin{array}{l}44 \text { and } \\
\text { older }\end{array}$ & $2(4.3)$ & \\
\hline
\end{tabular}

Out of the 149 women diagnosed with abnormal HSG findings, majority were in the 26 to 31-year-old age group ( $\mathrm{n}=53,35.6 \%)$, followed by 32 to 37 -year-old age group ( $\mathrm{n}=47,31.5 \%)$. A test for an association between type of HSG findings and age of women revealed that the proportion of women who had abnormal findings was not significantly different from the proportion of women who had normal findings across the various age groups. Therefore, there is no association between HSG findings (normal or abnormal) and age $(\mathrm{p}=0.2803)$. See Table 3.

Table 3: Distribution of women according to type of finding and age.

\begin{tabular}{|llll|}
\hline Age group & HSG finding & P-value \\
\hline & $\begin{array}{l}\text { Normal }(\mathrm{N}=70, \\
32.0 \%)\end{array}$ & $\begin{array}{l}\text { Abnormal } \\
(\mathrm{N}=149, \\
68.0 \%)\end{array}$ & \\
\hline $\mathrm{n}(\%)$ & & $4(2.7)$ & 0.2803 \\
\hline $20-25 \mathrm{y}$ & $4(5.7)$ & $53(35.6)$ & \\
\hline $26-31 \mathrm{y}$ & $22(31.4)$ & $47(31.5)$ & \\
\hline $32-37 \mathrm{y}$ & $27(38.6)$ & $41(27.5)$ & \\
\hline $38-43 \mathrm{y}$ & $13(18.6)$ & $4(2.7)$ \\
\hline $\begin{array}{l}44 \text { and } \\
\text { older }\end{array}$ & $4(5.7)$ & \\
\hline
\end{tabular}

P-value is Fisher's exact test of association between type of HSG finding and age.

The most common abnormality recorded was tuboperitoneal pathology in $112(75.2 \%)$ cases occurring alone or with coexisting uterine abnormality. Of the tubal pathology, bilateral tubal blockage occurred most frequently in $53(35.6 \%)$ cases and hydrosalpinx in $8(5.4 \%)$.
Salpingitis Isthmica Nodosa was the least observed pathology in $4(1.8 \%)$ cases of secondary infertility. Uterine fibroid was the prevalent endometrial abnormalities $(n=53,35.6 \%)$ and intrauterine adhesions was diagnosed in $30(20.1 \%)$ patients.

Table 4: Distribution of HSG findings by type of infertility.

\begin{tabular}{|c|c|c|c|}
\hline \multirow{2}{*}{ Findings } & \multicolumn{2}{|c|}{ Type of Infertility } & \multirow{2}{*}{ Pvalue } \\
\hline & Primary & Secondary & \\
\hline \multicolumn{4}{|l|}{ n $(\%)$} \\
\hline All & $47(21.5)$ & $172(78.5)$ & $\begin{array}{l}<0.000 \\
1 *\end{array}$ \\
\hline Normal & $19(40.4)$ & $51(29.7)$ & 0.1604 \\
\hline Abnormal & $28(59.6)$ & $121(70.4)$ & \\
\hline \multicolumn{4}{|c|}{ Tuboperitoneal abnormalities } \\
\hline \multicolumn{4}{|c|}{ Tubal blockage } \\
\hline Bilateral & $4(8.5)$ & $18(10.5)$ & \\
\hline Unilateral & $2(4.3)$ & $18(10.5)$ & \\
\hline \multicolumn{4}{|l|}{ Hydrosalpinx } \\
\hline Bilateral & $1(2.1)$ & $1(0.6)$ & \\
\hline Unilateral & $0(0.0)$ & $2(1.2)$ & \\
\hline \multicolumn{4}{|c|}{ Perifimbrial adhesions } \\
\hline Bilateral & $1(2.1)$ & $3(1.7)$ & \\
\hline Unilateral & $3(6.4)$ & $3(1.7)$ & \\
\hline \multicolumn{4}{|c|}{ Salpingitis isthmica nodosa } \\
\hline Bilateral & $0(0.0)$ & $2(1.2)$ & \\
\hline Unilateral & $0(0.0)$ & $2(1.2)$ & \\
\hline \multicolumn{4}{|c|}{ Cavitary Abnormalities } \\
\hline Fibroid & $6(12.8)$ & $14(8.1)$ & \\
\hline $\begin{array}{l}\text { Intrauterine } \\
\text { adhesions }\end{array}$ & $4(8.5)$ & $11(6.4)$ & \\
\hline Congenital & $0(0.0)$ & $2(1.2)$ & \\
\hline \multicolumn{4}{|l|}{ Co-morbidities } \\
\hline \multicolumn{4}{|c|}{ (i) Adhesions + Tubal Blockage } \\
\hline Bilateral & $1(2.1)$ & $5(2.9)$ & \\
\hline Unilateral & $0(0.0)$ & $4(2.3)$ & \\
\hline \multicolumn{4}{|c|}{ (ii) Adhesions + Hydrosalpinx } \\
\hline Bilateral & $1(2.1)$ & $2(1.2)$ & \\
\hline Unilateral & $0(0.0)$ & $1(0.6)$ & \\
\hline $\begin{array}{l}\text { (iii) Adhesions + } \\
\text { Perifimbrial } \\
\text { Pathology }\end{array}$ & $0(0.0)$ & $1(0.6)$ & \\
\hline \multicolumn{4}{|c|}{ Fibroid + Tubal Blockage } \\
\hline Bilateral & $4(8.5)$ & $21(12.2)$ & \\
\hline Unilateral & $1(2.1)$ & $7(4.1)$ & \\
\hline Others & $0(0.0)$ & $4(2.3)$ & \\
\hline $\begin{array}{l}\text { Total abnormal } \\
\text { findings }\end{array}$ & 28 & 121 & \\
\hline
\end{tabular}

Tubal pathology occurred singly in 64 (43\%); 37 (24.8\%) had uterine cavitary abnormality alone, while a relatively high percentage $(n=112,75.5 \%)$ had combined endometrial and tubal pathology with uterine fibroid and coexisting bilateral tubal blockage predominating $(n=25$, $16.8 \%)$.

The least common anomaly diagnosed was congenital anomaly $(n=2,1.3 \%)$ which included a case each of 
Binornuate and septated uterus. See Table 4 and Figures $2,3,4$.

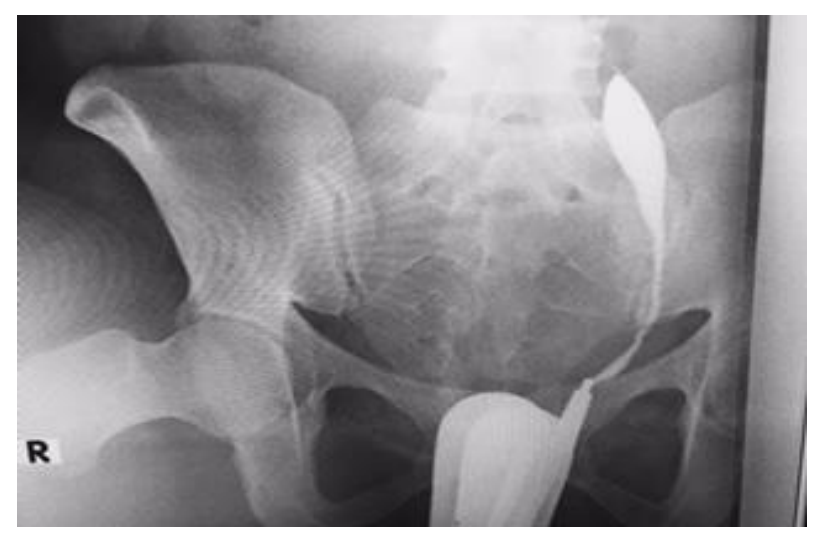

Figure 2: HSG showing elongated distorted endometrial canal secondary to uterine mass.

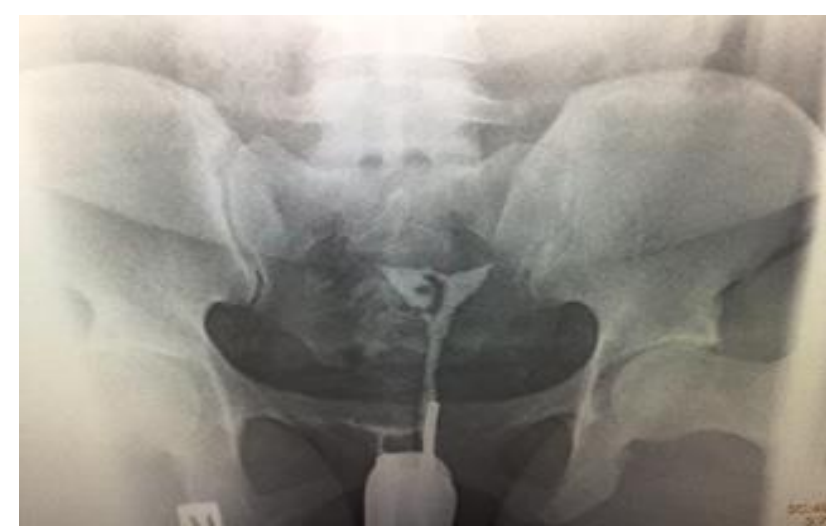

Figure 3: HSG showing linear filling defects consistent with intrauterine adhesions.

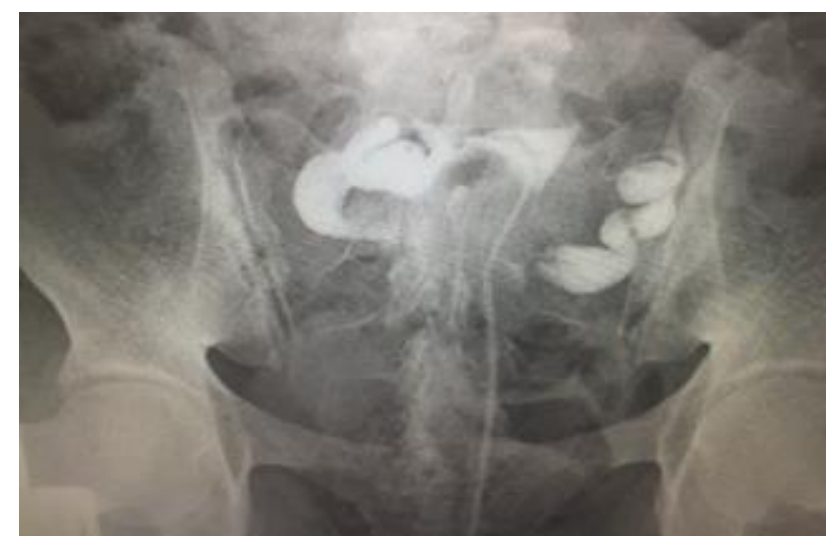

Figure 4: HSG showing dilated contrast filled tubes without peritoneal spillage consistent with bilateral hydrosalpinx.

\section{DISCUSSION}

Infertility is generally considered primary if no pregnancy has ever occurred between the couple and secondary if an earlier confirmed pregnancy had been achieved. Infertility can be due to the male factor when there is disorder in number or morphology of semen and other male related structural abnormalities. Female factor infertility can be caused by fallopian tube occlusion, uterine or endometrial abnormalities, stenosis or incompetence of the cervix and anovulation. Both partners could contribute at different degrees to the Infertility or no cause may be found. About $30 \%$ of infertility is due to female problems, $30 \%$ to male problems, and $30 \%$ to combined male/female problems, while in $10 \%$, there is no recognizable cause. ${ }^{9}$ These figures are however dependent on the location of study.

The study revealed that the age group most frequently investigated for primary infertility is 26-31years and secondary infertility in a slightly older age group (32-37 years). The findings carried out in other regions of Nigeria did not make any differentiation in the type of infertility but instead recorded similar ranges as our study. ${ }^{10-14}$ Secondary infertility was commoner than the primary type In this study $(78.5 \%$ vs $21.5 \%)$ in keeping with the findings of others in Africa. ${ }^{12,15}$ This higher rate of patients with secondary infertility compared to primary infertility can be used as a crude indicator of the possible effects of PID, postabortal sepsis and puerperal sepsis in our setting. ${ }^{16}$ This also mirrors the general infertility trend in Nigeria and sub-Saharan Africa which has been attributed to the sequelae of poorly managed pelvic inflammatory disease resulting in utero-tubal damage and or pelvic adhesions. ${ }^{17}$ This finding differs from that done in Thailand which shows that primary infertility occurred in $72 \% \%$ of cases. ${ }^{18}$

The higher primary infertility rate $(65 \%)$ reported by Ikechebelu et al may be due to the inclusion of male partners in their study which revealed a greater contribution of male factors to infertility. ${ }^{19}$ We only reviewed female factor infertility. Examination is said to be normal when the uterine cavity shows no structural abnormalities or filling defects with normal caliber fallopian tubes showing free spillage of contrast into the peritoneal cavity. Our study showed a higher percentage of abnormal findings (68\%) similar to studies done in southeast and South of Nigeria but contrasts with a study done in Nigeria's North East which recorded a higher normalcy rate of $62.41 \% \cdot{ }^{10,14,20}$ Cultural and religious differences were adduced for the dissimilarity in findings. Male infertility as a contributor is often ignored and therefore male infertility workup is often not done due to different cultural reasons including that infertility is considered as a female problem ${ }^{21}$ Most of the women with abnormal findings were between the ages of 26-31 years $(n=53,35.6 \%)$, followed by $32-37(n=47,31.5 \%)$ This finding reaffirms the age distribution pattern in other institutions from Nigeria and elsewhere. ${ }^{12,20}$ There is however no association between HSG findings (normal or abnormal) and age $(\mathrm{p}=0.2803)$. Women with secondary infertility had a higher rate of abnormal HSG findings than women with primary infertility $(81.2 \%$ 
versus $18.8 \%$, respectively) similar with the study done in Thailand which showed that women with secondary infertility were 2.4 times more likely to have abnormalities. ${ }^{22}$ This corroborates the claim that infertility could be due to inadequate care during previous pregnancies or previous abortions resulting in pelvic infections. $^{12}$ The main purpose for carrying out hysterosalpingographic investigations is for the evaluation of the patency of the genital tracts seen as opacification with free intraperitoneal spillage of contrast. Blockage of the tubes can be as a result of infection, previous surgical intervention within the Uterus or mechanical factors such as masses or adhesions. In Nigeria, tubo-peritoneal factors have been shown to be the commonest cause of infertility, contributing to as much as $64 \%$ in some series due to high prevalence of sexually transmitted infection. ${ }^{23}$

Tuboperitoneal pathology was the most common abnormality seen in our study, occurring singly in 64 $(43 \%)$ patients and coexisting with an endometrial pathology in $48(32.2 \%)$ of the abnormal cases. A similar study in Burkina Faso recorded an even higher incidence $(62 \%)$ of tubal pathology. ${ }^{15}$ A co morbidity rate of $12 \%$ was recorded by Danfulani et al, while Eleje et al recorded $22.6 \% .^{11,13}$ Of all the abnormal cases, Tuboperitoneal lesions occurred in $94(63 \%)$ of secondary infertility patients and in only $18(12 \%)$ of patients with primary infertility in contrast with the study in Ilorin, Nigeria which shows that bilateral blockage was commoner in primary infertility $(42.11 \%$ vs $32 \%)$. This study using sonohysterosalpingography, SHSG also established that there is no statistically significant difference $(p=0.237)$ between the results of the two methods (HSG and SHSG). ${ }^{24}$ Higher incidence of uterine than tubal factor infertility was reported in the south east of Nigeria. ${ }^{10}$ Bilateral tubal occlusion which occurred in $35.6 \%$ of all abnormal cases was the commonest tubal anomaly, same as previous studies in Africa. ${ }^{13-15}$ This is followed by unilateral occlusion in $21.5 \%$.Unlike the previously mentioned studies which showed right or left sided preponderance, our study showed that the two sides were almost at par. The Pakistani study involving a larger data of 4,108 revealed unilateral blockage to be more common than bilateral blockage $(15 \%$ vs $10 \%){ }^{25}$ In a study done in Port Harcourt only $4 \%$ had bilateral tubal occlusion but they reported a higher incidence of hydrosalpinges $(15.2 \%){ }^{26}$

Hydrosalpinx, a sequela of distal tubal occlusion leading to dilatation of the proximal segment was seen in only 8 cases $(5.4 \%$ )women, much less than in similar studies done by Adetiloye (44.5\%) and Bello (23.3\%). ${ }^{16,27}$ These are older studies and the lower value in our study may be due to improved health care delivery system over the years. Salpingitis isthmica nodosa, rare disorders seen as outpouchings from the tubes especially the isthmic portions were seen in $4(2.7 \%)$ cases of patients, all with secondary infertility. It is significantly associated with recurrent ectopic pregnancies and infertility with a wide range of incidence $(2.8 \%-57 \%) .{ }^{28}$

Perifimbrial adhesion are fibrous tissue that form secondary to a healed pelvic infection or any form of trauma and is evidenced by loculated and restricted spillage of contrast on HSG. The scar tissue can be seen on laparoscopic investigations but only inferred on HSG.The incidence of perifimbrial adhesions in this study is $6.7 \%$. This is particularly noteworthy considering that a Study done in Nigeria has shown that with good case selection, therapeutic hydrotubation may be beneficial in resource poor countries, especially in patients with incomplete tubal occlusion (bilateral perifimbrial adhesions) and as part of treatment for unexplained infertility. ${ }^{29}$

Uterine cavitary abnormalities include any pathology that causes a distortion of the normal hysterosalpingographic anatomy of the endometrial cavity. These contour abnormalities could be caused by uterine fibroid, synechiae, adenomyosis, congenital abnormalities and intracavitary polyps. The different patterns of presentation on HSG will lead to the most likely diagnosis. Further evaluation with Ultrasonography, sono HSG, MRI is recommended in some cases for definitive diagnosis.

Of the uterine cavity abnormality recorded, 37 (24.8\%) occurred with patent tubes while a slightly higher number, $48(32.2 \%)$ had coexisting tuboperitoneal pathology thereby increasing morbidity. Intrauterine fibroid was the most commonly acquired cavity abnormality seen in our study $(n=53,35.6 \%)$ followed by uterine synechiae $26(20.1 \%)$. Uterine fibroids are the most common tumors in women of reproductive age and lead to impairment of reproductive functions resulting in reduced fertility, early pregnancy loss, increased preterm labor and delivery, and marked increase in the risk for cesarean delivery. ${ }^{30}$

The position and size of the fibroid is important because it can also cause tubal blockage. In a series of 13 infertile women by Corson and Brooks a pregnancy rate of $76.9 \%$ was observed after hysteroscopic myomectomy. ${ }^{31}$ Intrauterine Adhesions are scar tissue within the endometrium secondary to infection or trauma to the endometrial lining and are seen as irregular filling defects within the contrast opacified uterine cavity. The high incidence in our study most likely highlights the effects of poorly treated endometrial infections and possibly unsafe abortions. In agreement with previously mentioned studies in our environment the fact that majority of factors contributing to infertility is acquired is supported by our study that shows only 2 congenital anomalies. A case each of Binornuate and septated uteri were seen.it is noteworthy that these were associated with blocked tubes and patients who presented with secondary infertility. 


\section{CONCLUSION}

Hysterosalpingography remains very important in the investigation of infertility in our centre with tuboperitoneal pathology as the major contributor to female infertility. The high incidence of tuboperitoneal factor and intrauterine adhesions found in this study further supports infection as the leading cause of infertility in our environment. These acquired causes of infertility are largely preventable. The primary prevention and prompt treatment of infections are indispensable measures that must therefore be put in place to reduce the high incidence of infertility.

\section{Funding: No funding sources}

Conflict of interest: None declared

Ethical approval: The study was approved by the Institutional Ethics Committee

\section{REFERENCES}

1. Okonofua FE, Odunsi K. Infertility in Sub-Saharan Africa. In: editors. contemporary obstetrics and gynaecology for developing countries. Publishers: Women's Health and Action Research Center. Benin City. 2003;128-56.

2. Idrisa A, Emuveyan EY. Infertility. In: Kwawukume editors. Comprehensive gynaecology in the tropics. Accra Graphic Packag. 2005:333-43.

3. Poonam S. The role of hysterosalpingography in cases of subfertility. KUMJ. 2007;5:456-60.

4. Danielle E. Luciano MD, Exacoustos C, Johns DA. Can contrast hystezrosalpringo-sonography replace hysterosalpingography in confirming tubal blockage after hysteroscopic sterilization and in the evaluation of the uterus and tubes in infertile patients? AM J Obstet Gynecol. 2011;204(79):1-5.

5. Aremu A, Adetiloye A, Ibitoye B, Adekanle D, Bello T. Transabdominal saline contrast sonohysterography: can it replace hysterosalpingography in low resource countries? J Clinic Diagno Res. 2012;6:239-42.

6. Den Hartog JE, Lardenoije CM, Severens JL and Kessels AG. Screening strategies for tubal factor subfertility. Hum Reprod. 2008;23:1840-8.

7. Mohammad Beigi R, Tanhaeivash R. Comparison of hysterosalpingography and laparoscopy in infertile Iranian women with tubal factor. Ginekol Pol. 2012;83:841-3.

8. Waheed S, Mazhar R, Khan NH, Rafi M. The Comparison of Hysterosalpingography and Laparoscopy in Predicting Fertility Annals. 2007;13:202-5.

9. Inhorn MC. Global infertility and the globalization of new reproductive technologies: Illustrations from Egypt. Soc Sci Med. 2003;56:1837-51.

10. Okafor CO, Okafor CI, Okpala OC, Umeh E. The pattern of hysterosalpingographic findings in women being investigated for infertility in Nnewi, Nigeria. Niger J Clin Pract. 2010;13:264-7.
11. Danfulani M, Yunusa GH, Ma'aji SM, Sa'idu SA, Musa MA. Tubal abnormalities on hysterosalpingography in primary and secondary infertility in Sokoto, Northwestern-Nigeria. Asian Journal of Medical Sciences. 2014;6(2):47-50.

12. Kiguli-Malwadde E, Byanyima RK. Structural findings at hysterosalpingography in patients with infertility at two private clinics in Kampala, Uganda. Afr Health Sci. 2004; 4:178-81.

13. Eleje G, Okaforcha E, Umeononihu OS, Udegbunam OI, Etoniru IS, Okwuosa AO. Hystero salpingographic findings among infertile women: review at a tertiary health care institution in Nnewi, South-east Nigeria. AFRIMEDIC J. 2012;3(2):20-3.

14. Eze CU, Ohagwu CC, Abonyi LC, Njoku J, Irurhe NK, Igbinedion FO. A Spectrum of Hysterosalpingographic Findings in Infertile Women in Benin City, Nigeria. J Reprod Infertility. 2013;4(2):13-8.

15. Cisse R, Louge C, Ouedraogo A, Thieba B,Tapsoba T, Ouedraogo CM, et al. Features of Hysteroslpingography performed in Burkina Faso. J Radiol. 2003:83(3):361-4.

16. Bello TO. Pattern of tubal pathology in infertile women on hysterosalpingography. Ann Afr Med. 2004;3:72-9.

17. Idrisa A, Ojiyi E. Pattern of infertility in NorthEastern Nigeria. Trop J Obstet Gynaecol. 2000;17:27-9.

18. Sinawat S, Pattamadilok J, Seejorn K. Tubal abnormalities in Thai infertile females. J Med Assoc Thailand. 2005;88(6):723-7.

19. Ikechebelu JI, Adinma JIB, Orie EF, Ikegwuonu SO. High prevalence of male infertility in Southeastern Nigeria. J Obstet Gynaecol. 2003;26(6):657-9.

20. Abubakar M, Njiti M, Mathew E, Abubakar A, Joseph D, Moi S. Evaluation of hysterosalpingographic (HSG) findings among suspected infertile women at Abubbakar Tafawa Balewa University Teaching Hospital (ATBUTH) Bauchi. Int Res Med Sci. 2016;3:55-9.

21. Dyer SJ, Abrahams N, Mokoena NE, van der Spuy ZM. You are a man because you have children: experiences, reproductive health knowledge and treatment-seeking behavior among men suffering from couple infertility in South Africa. Hum Reprod. 2004;19(4):960-7.

22. Nampakdianan K, Kielpeerakool C, Chongpensuklert Y. Abnormal Hysterosalpingographic Findings in Infertile Women. Thai J Obstet Gynaecol. 2016:24(3):209-15.

23. Idrisa A, Ojiyi E. pattern of infertility in NorthEastern Nigeria. Trop J Obstet Gynaecol. 2000;17:27-9.

24. Oguntoyinbo AE, Amole OA, Komolafe OA. Sonographic Assessment of Fallopian Tube Patency in the Investigation of Female Infertility in Ilorin, Nigeria. Af J Reprod Health/ La Revue Africaine De La Santé Reproductive. 2001;1:100-05. 
25. Aziz MU, Anwar S, Mahmood S. Hysterosalpingographic evaluation of primary and secondary infertility. Pak J Med Sci. 2015;31(5):1188.

26. Nwankwo NC, Akani CI. Pattern of hysterosalpingographic findings in infertility in Port Harcourt. West African J Radio. 2005;12:15-9.

27. Adetiloye VH. Radiological patterns of diseases on Hysterosalpingography. Dissertation. National Postgraduate Medical College of Nigeria, Lagos. 1988;64-100.

28. Majumdar B, Henderson PH, Semple E. Salpingitis isthmica nodosa: A high risk for tubal pregnancy. Obstet Gynecol Surv. 1983;62:73-8.
29. Adesiyun AG, Cole B, Ogwuche P. Hydrotubation in the management of female infertility: outcome in low resource settings. East Af Medic J. 2009;86(1):31-6.

30. Ciavattini A, Di Giuseppe J, Stortoni P, Montik N, Giannubilo SR, Litta P et al. Uterine Fibroids: Pathogenesis and interactions with endometrium and endomyometrial junction. Obstet Gynecol Int. 2013; 173:84

31. Corson SL, Brooks PG. Resectoscopic myomectomy. Fertil Steril. 1991;55:104-14.

Cite this article as: Itanyi UD, Oluseyi HO. Spectrum of hysterosalpingographic findings among women presenting with infertility in Abuja, Nigeria's capital. Int $\mathrm{J}$ Reprod Contracept Obstet Gynecol 2017;6:1583-9. 